\title{
القوة الثبوتية للمحاضر في مادة الجنح
}

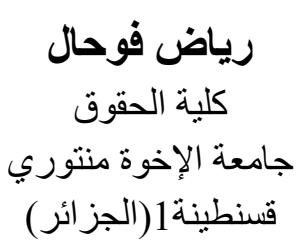

لا جريمة و لا عقوبة إلا بنص قانون، و لا إدانة بأية

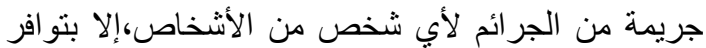

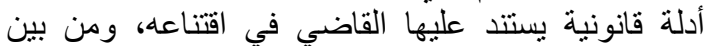
الجرائم الأكثر انتشار النة جرائم الجنح وأهم وسائل إثابتها

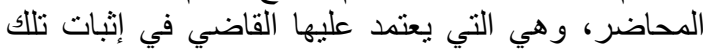

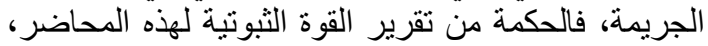

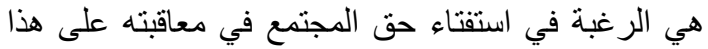

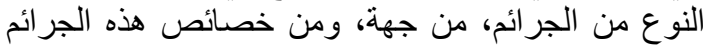
أنها لا تترك أثر ا بسهل الحفاظ علئ عليه للاليل على ارتكاب الجريمة و الكثف عن فاعلها، فالفاعل يعمل على إخفاء أثنار الجريمة ، أما رجل القانون يعمل على كثف إنف الحقيقة و القضاء على الجريمة. المبة.

الكلمات المفتاحية: المحاضية: المرية، القوة الثبوتية جرائم

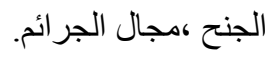

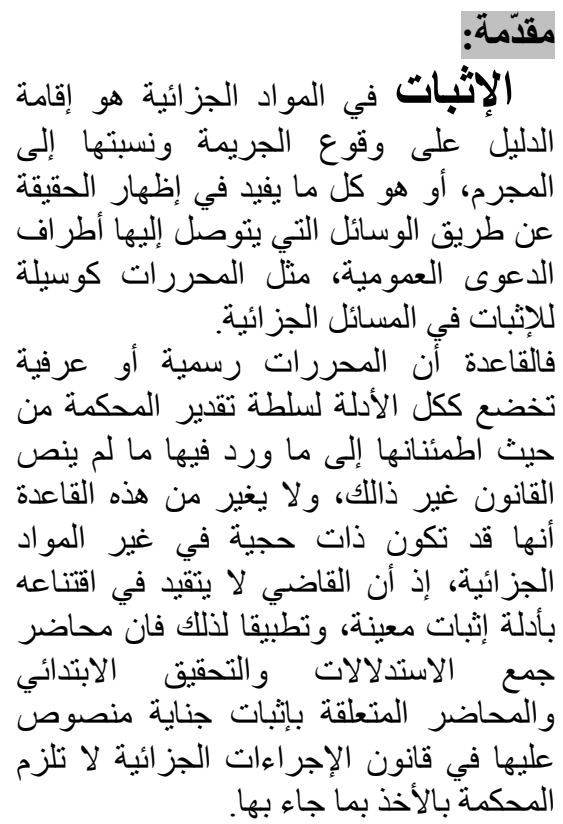

\begin{abstract}
:
There is no offence or any sentence unless referred to or identified as such by the law and no sentence of any crime for anybody except if legal evidence is available so as to convince and enable the judge to take a decision.

There are many widespread (common) crimes and the most important means of their existence is the transcripts which the judge focuses on to say whether there is a crime or not.

What is wise from this conclusive force of these transcripts is the desire to fulfil the right of the society to punish this kind of offence. And some of the aspects of these crimes is that they do not leave any trace to be easily considered as an evidence for committing crime and to find out the criminal since the offender works hard to hide its trace whereas the task of the man of the law is unveil the truth and fight crime.
\end{abstract}


و هذا كأصل عام غير أن هناك استثناء على الأصل ما لم ينص القانون على غير ذلكا.

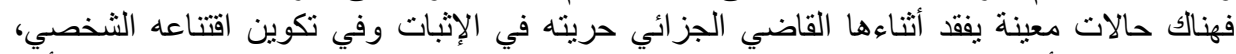

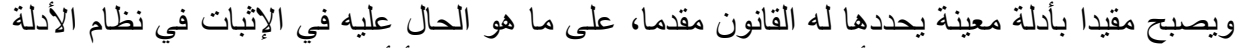

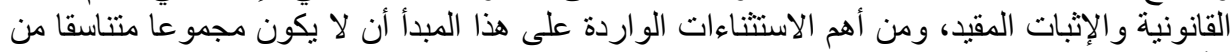

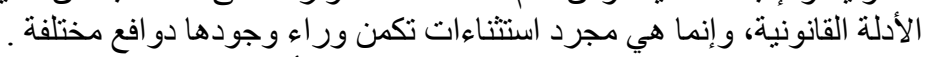

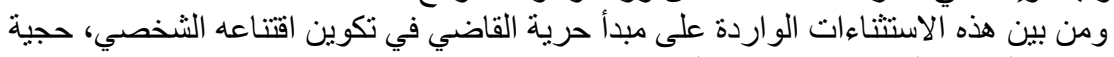

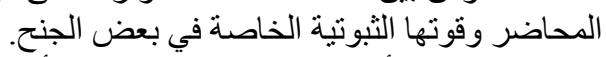

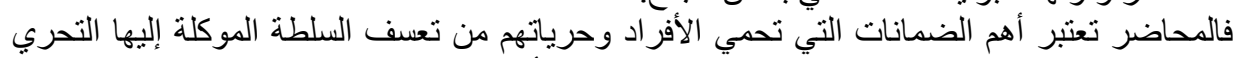

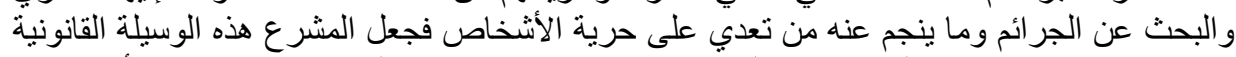

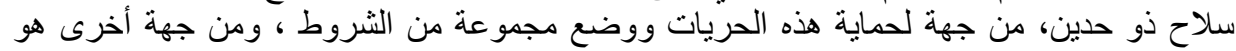

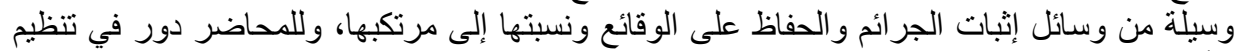

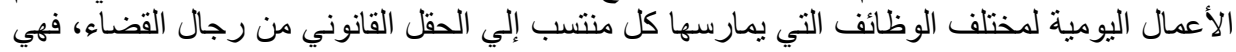

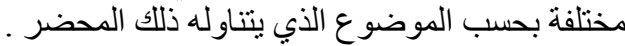

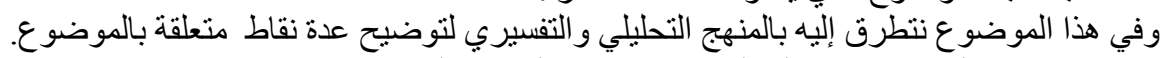

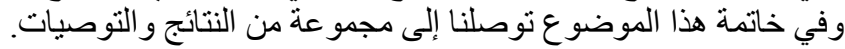
ومن خلال كل ما تقدم نطر ح الإنشال التالئي:

ما هي القيمة القانونية للمحاضر في إنبات جرائم التئم الجنح ؟

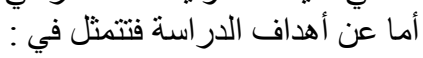

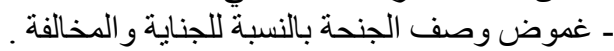

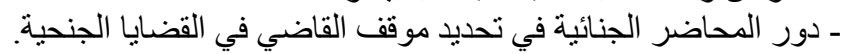

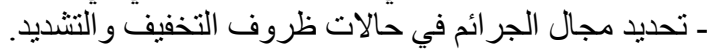
وسنتناول الموضو عن من خلال المباحث التالية:

المبحث الأول: القيمة القانونية للمحاضر في مادة الجنح.

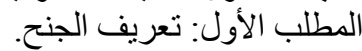

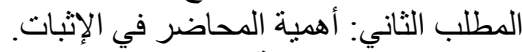

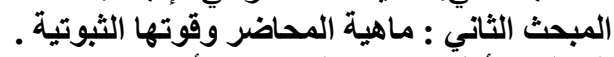
المطلب الأول: تعريف المحاضئ المداضر وأنو اعها.

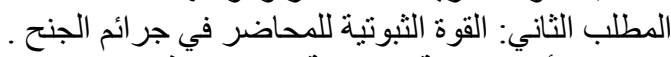

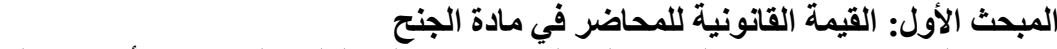

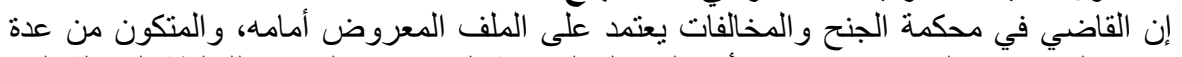

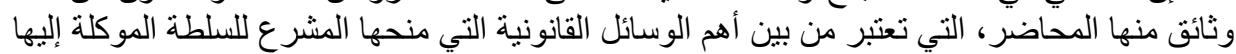

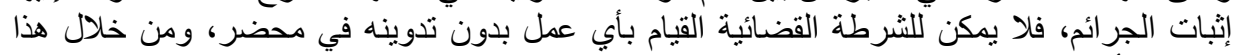

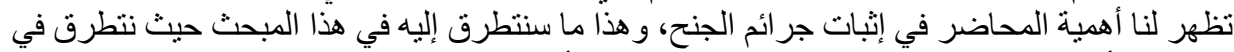
المطلب الأول إلى ماهية الجنح، وفي المطلب الثناني إلى أهمية المحاضر في الإنبات في الثبات.

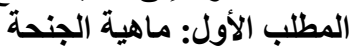

وفي هذا المطلب سوف نتطرق إلى تعريف جرائم الجنح سواء من الناحية القانونية أو الفقهية وهذا

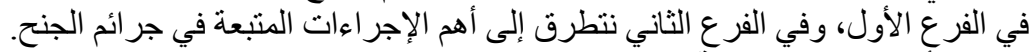

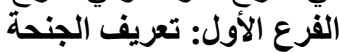

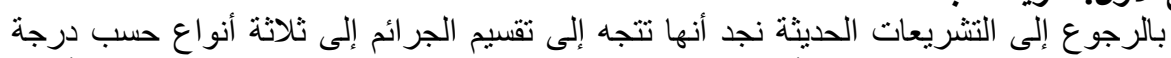

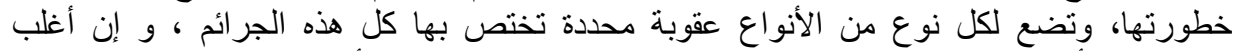

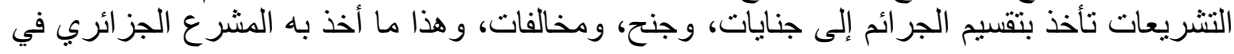




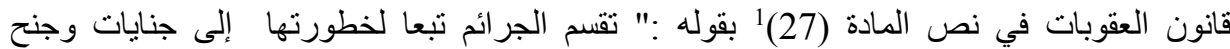

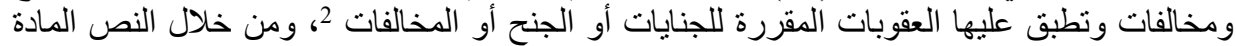

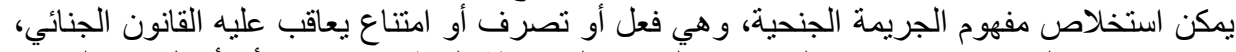

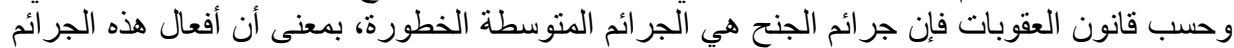

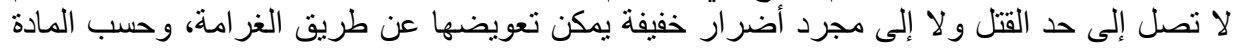

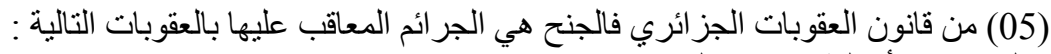

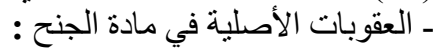

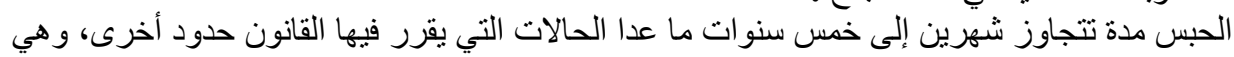
عقوبة تقوم على سلب حرية المحكوم عليه.

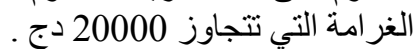

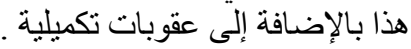
فالجنحة نوع من الجر ائم تتوسط الجناية و المخالفة رغم ارتباطها بظرفي التتديد و التخفيف، فلا يمكن تغيير وصفها الجنائي.

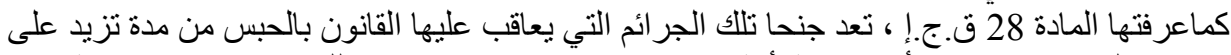

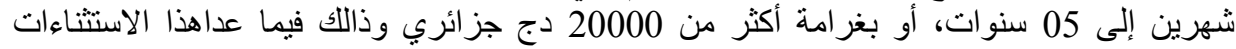

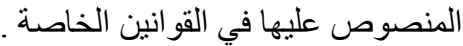

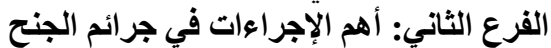

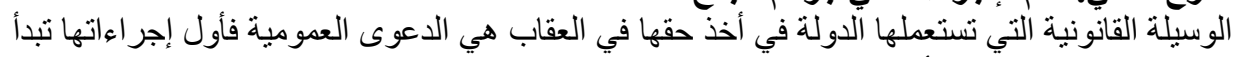

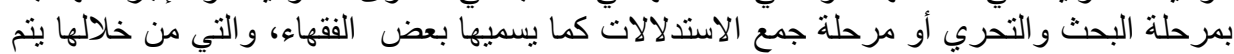

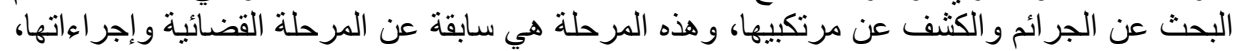

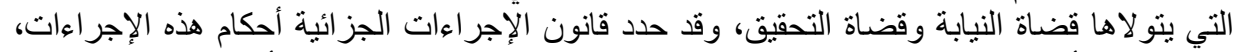

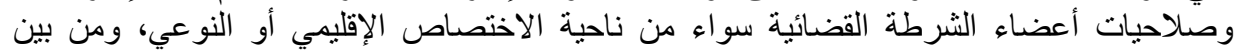

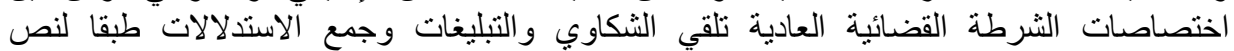

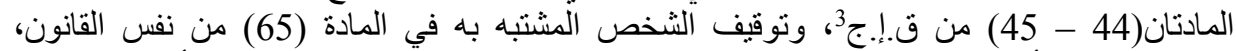

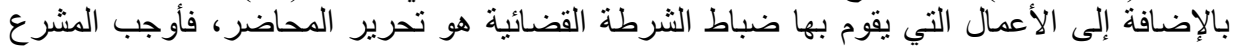

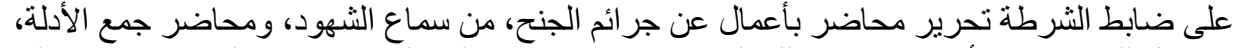

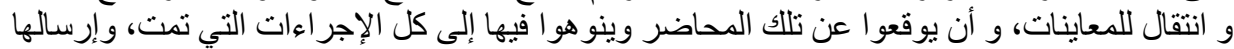

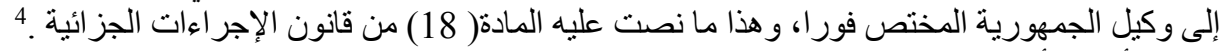

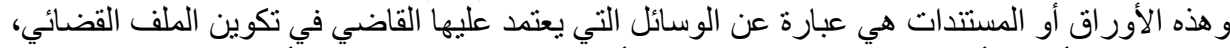

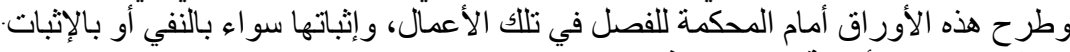
المطلب الثاني : أهمية المحاضر في الإثبات الثيات

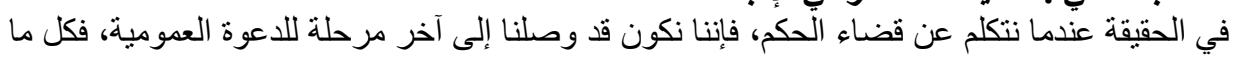
يتعلق بالجريمة والمسؤولية الجنائية يدخل في نطاق مهمة قضاء الحكاء الحكم، فنكون حينئذ بصدد الإثبات الجنائي في مداه النهائي 18.

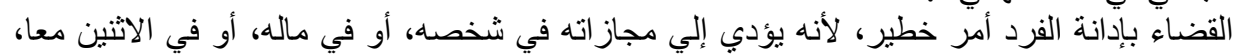

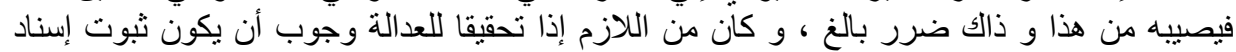

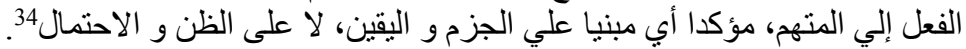

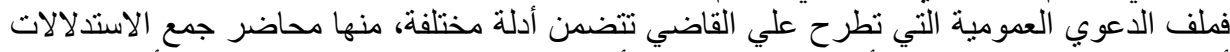

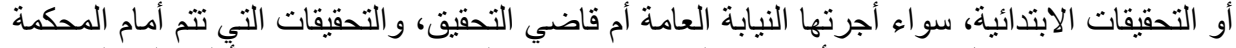

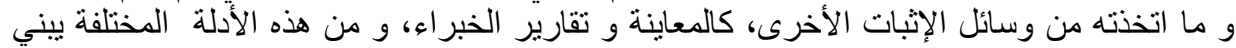

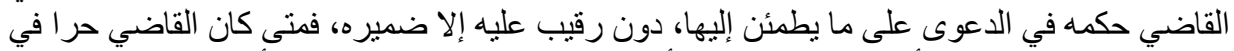

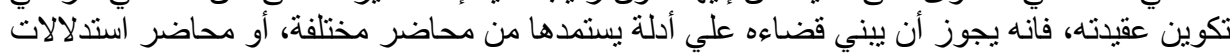


فقط، بل يجوز أن يكون عماد القضاء بالمحاضر، فالمحاضر التي يحررهاو كيل الجمهورية لإثبات

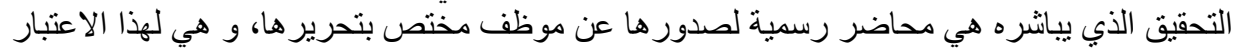

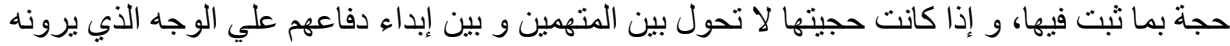

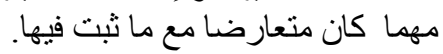

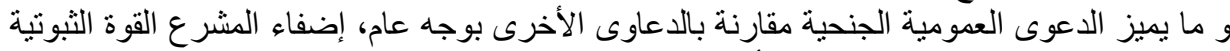

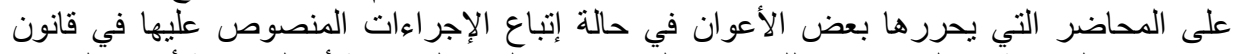

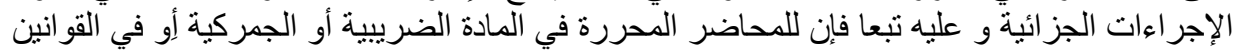

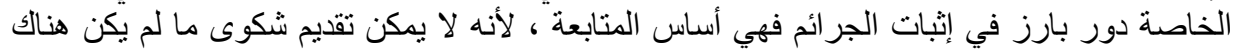

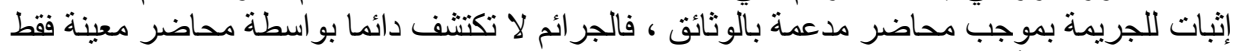

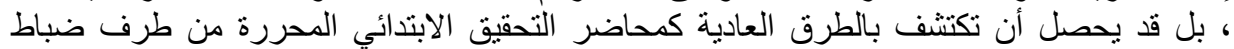

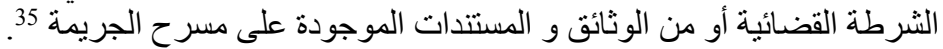

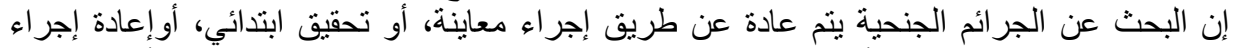

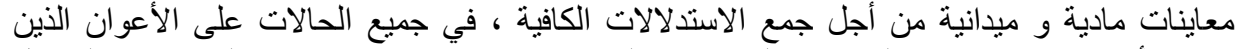

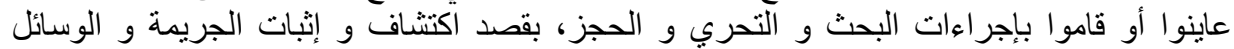

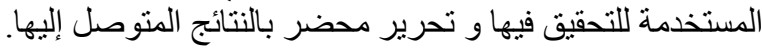

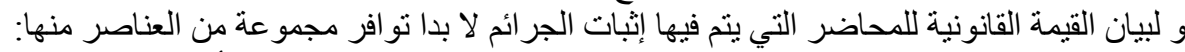

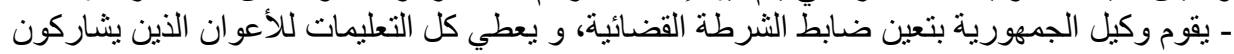

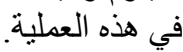

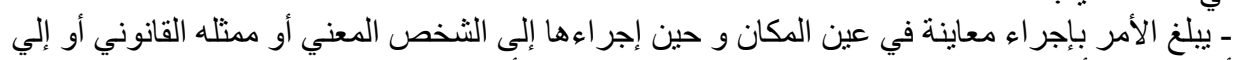

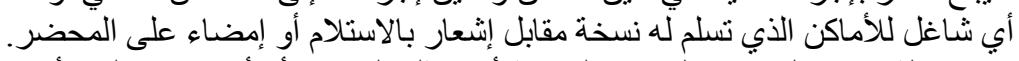

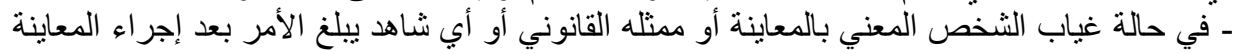

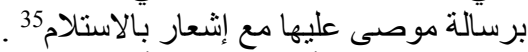

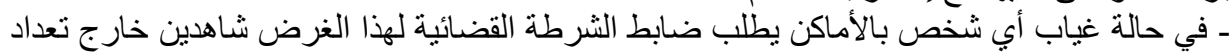

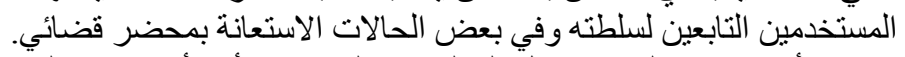

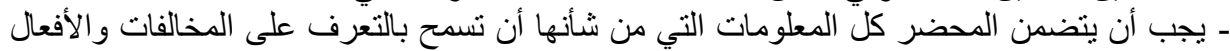

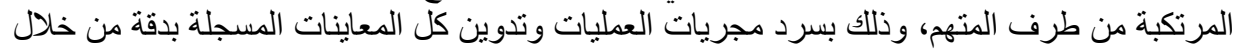

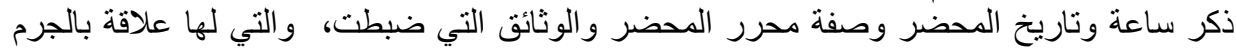

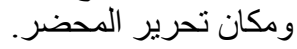

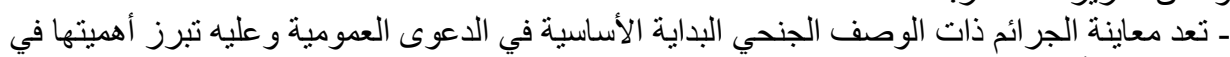

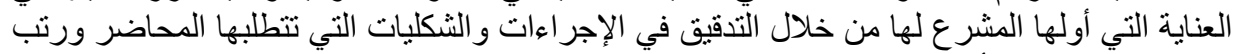

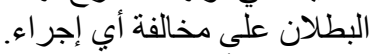

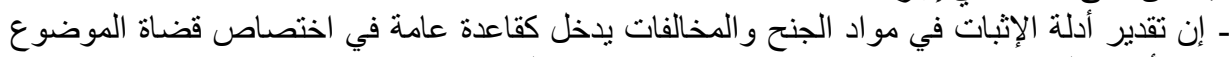

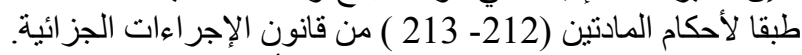

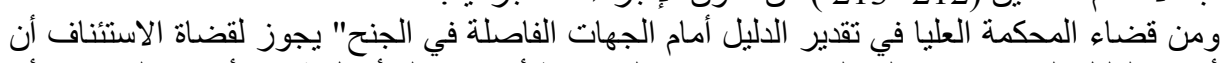

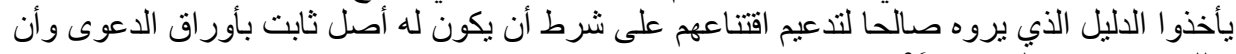

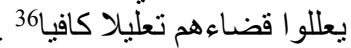

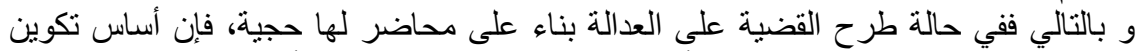

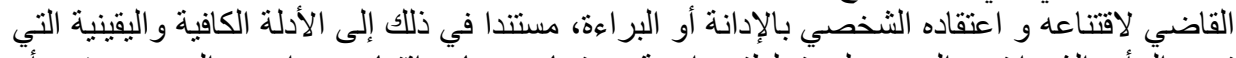

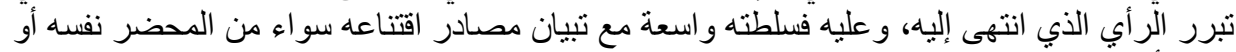

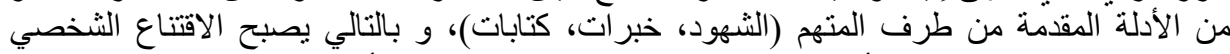
اقتتاعا موضو عيا، بالرغم من أن للقاضي كامل الحرية في البحث عن الأدلة، و تقديمه الثخصي لإن لها، و 
الاطئنانه إليها، و عليه تبيان ذلك في حكمه، مما يحقق نوازنا بين حرية الاقتناع و الدليل على صحة

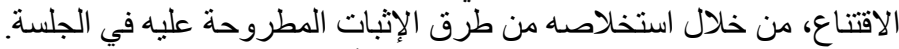

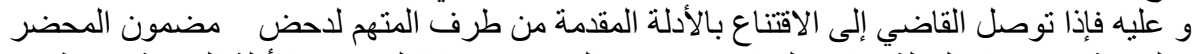

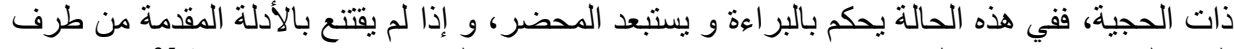

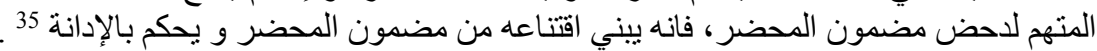

المبحث الثاني : ماهية المحاضر وقوتها الثبوتية

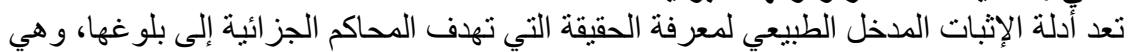

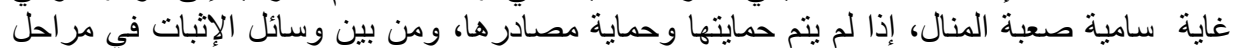

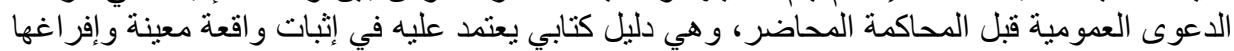

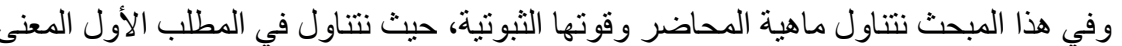

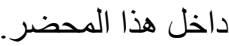

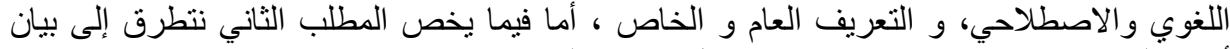

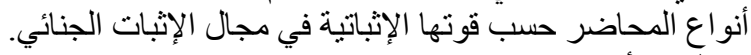
المطلب الأول: تعريف المحضر

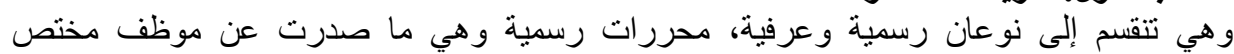

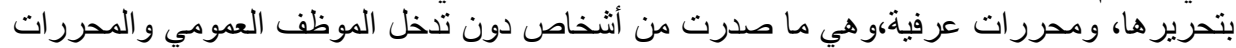

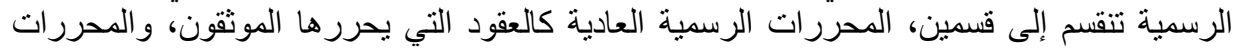

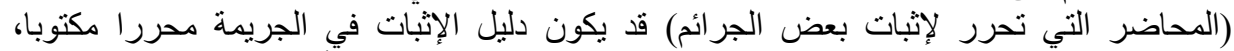

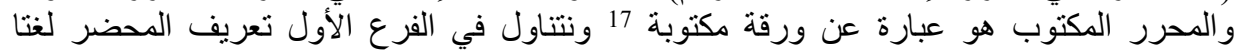

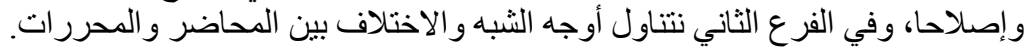

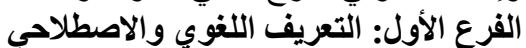

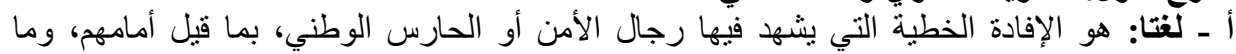

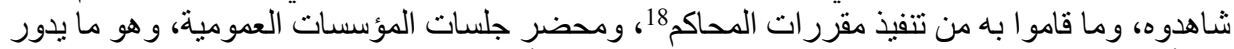

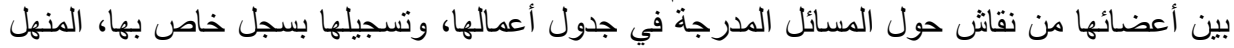

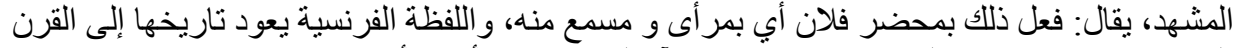

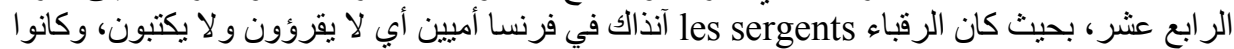

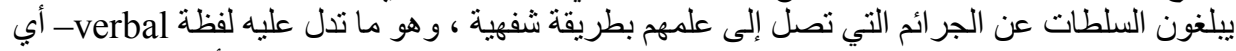

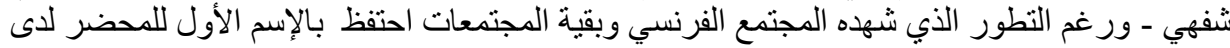
المستعطلين للغنة الفرنسية الفية 19. بـ اصطلاحا: إن التعريف الاصطلاحي للمحضر يمكننا أن نقسمه إلى تعريف عام وتعريف خاص على

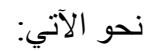

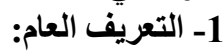

المخر هو الصطلاح يطلق على الأوراق والمستتدات التي بسجل فيها شخص أو أكثر مؤهل ( عادة

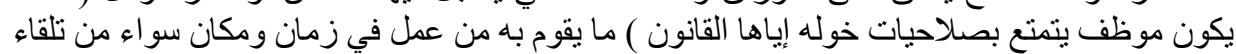

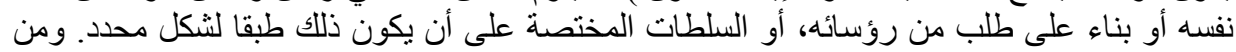

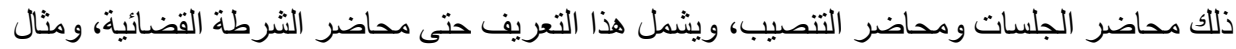

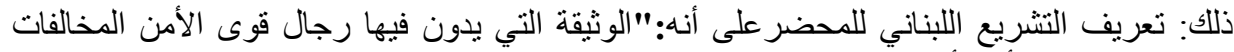

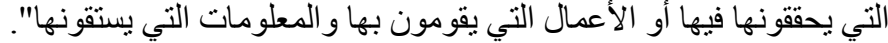

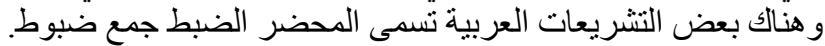

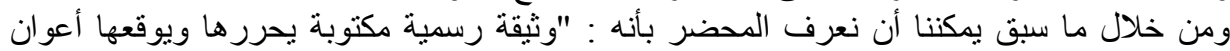
الثرطة القضائية طبقا للأشكال التي حددها القانون أو التنظيم، أو بعبارة أخرى هو الوسيلة المعتادة التي 
يبلغ بو اسطتها أعوان الثرطة القضائية السلطة القضائية بما يقومون من أعمال يخولهم إياها القانون" 20

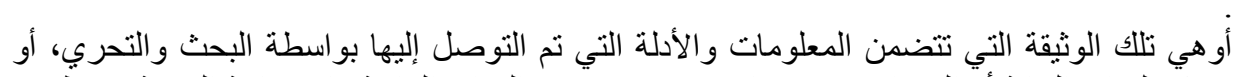

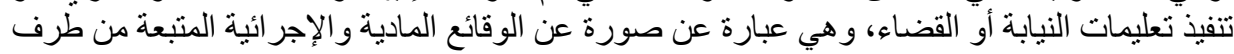

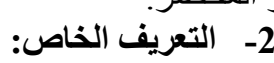

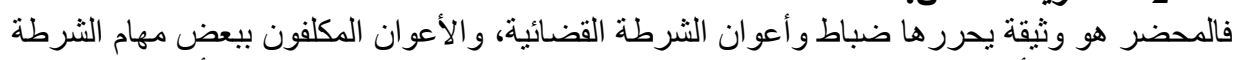

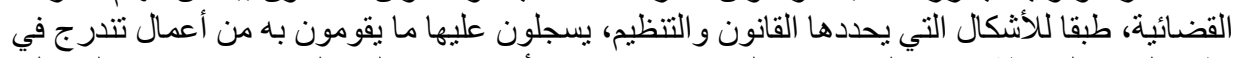

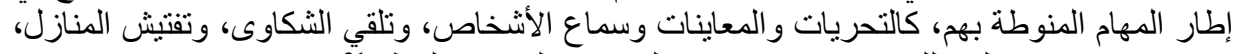

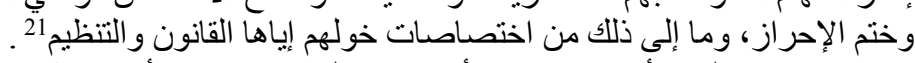

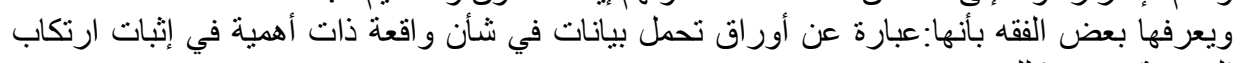

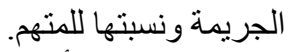

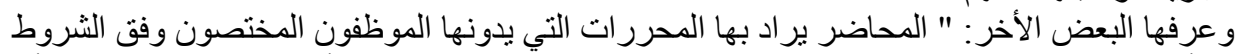

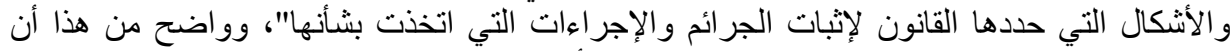

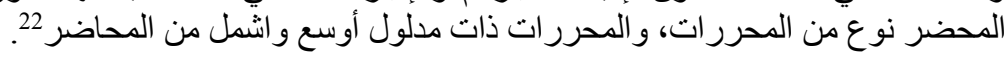

الفرع الثاني: أوجه الثبه والاختلاف بين المحاضر والمحررات

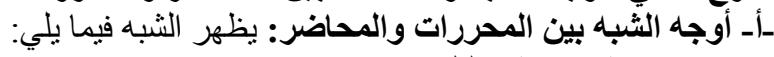

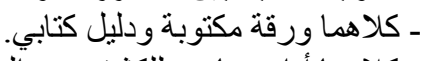

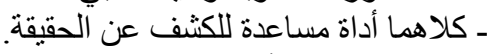

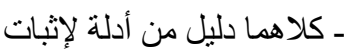

ب- أوجه الاختلافات بين المحررات ولات والمحاضر :ويظهر فيما يلي: ـ المحررات بمكن أن تصدر من أي شخص حتى من المتهم نفسه، وبالتالي قد تكون رسمية أو

ـ ـ أمبا. المحاضر فلا يمكن أن تصدر إلا من شخص مختص قانونا بإصدارها، وبالتالي تكون دائما

رسمية.

والمشرع الجزائري اعتبر المحاضر كدليل من أدلة الإثبات الجنائي في المواد من 214 إلى 218 من قانون الإجراءات الجزائية ولم يذكر المحررات.

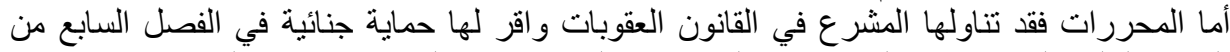
الكتاب الثالث الذي عنوانه التزوير في المحررات الرسمية، في المواد من 197 إلى في 213 من قانون الكان

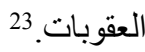
ويختلف المحرر العمومي عن المحرر الرسمي على النحو الآتي :

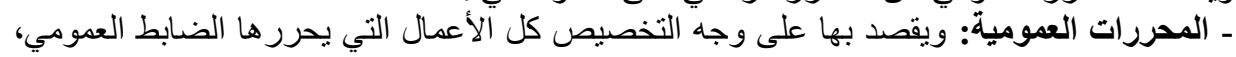

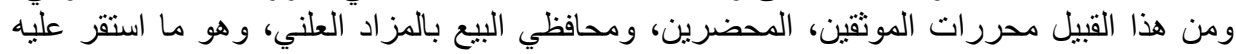
القضاء الفرنسي. ـ ـ المحررات الرسمية: اجمع الفقه و القضاء على توزيعها على ثلاث فئات:

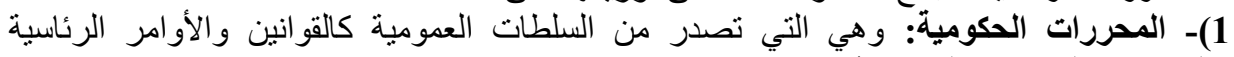

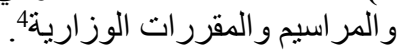

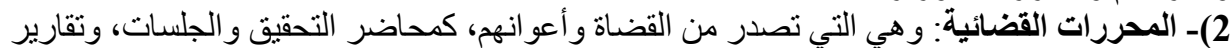
الخبر اء، و الأحكام والقرارات ونسخها، وكذا شهادات الاستئناف و المعارضة، و والطعن بالنقض فئهات، 
3)- المحررات الإدارية: وهي أكثر عددا من سابقتاها، وتثمل كل ما يصدر عن السلطات الإدارية

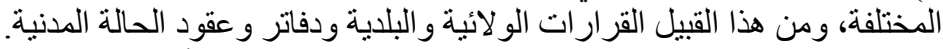

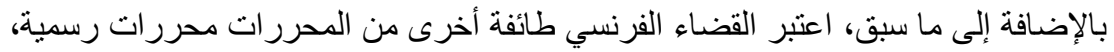

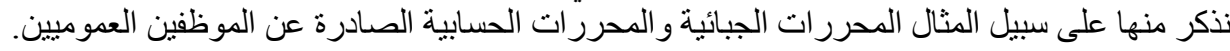
ج- تميز المحررات عن التقارير:

التقارير أو التقرير قد يحدث أثناء التحقيق في الجريمة سواء أمام قاضي التحقيق أو أمام قاضي أندي

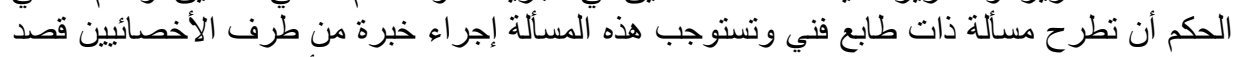

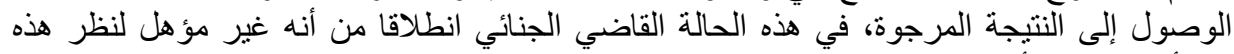

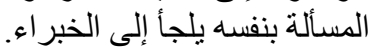

هؤ لاء الخبراء بعد قيامهم بالمهام المسندة لهم، يحررون تقارير الخبرة أو تقرير الخبرة بحسب ما إذا كان الثخص المعني واحدا أو أكثر.

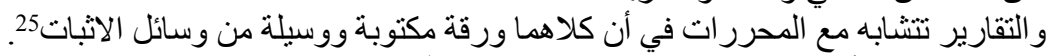

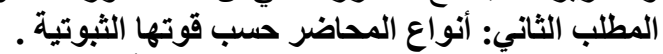

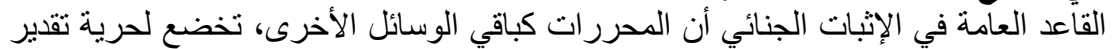

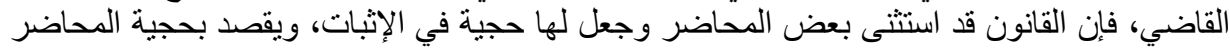

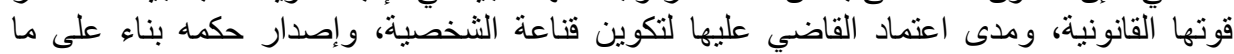
يستخلص منها من أدلة و إثبات، شريطة أن تكون صحيحة في الثكل ويكون قد حرره ذو صنفة صناء أثناء مباشرة الأعمال و الثروط الثلة وانبونية. ومن خلال هذا فان حجية المحاضر في الإثبات قد نو لاها المشرع ونظمها في ثلاث درجات

أو ثلاث أنوع وهي: ألمات

1- المحاضر التي تعتبر مجرد استدلالات أو (محاضر على سلى سبيل الاستدلال)

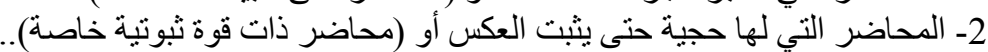

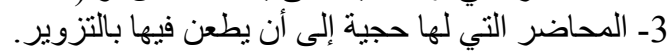

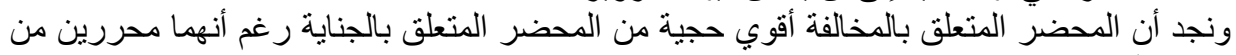
طرف الجهة ذانها 26.

و الإجر اء التي تتناولها الحجية في المضضر، هي ما تعلق بالإثبات و ما عاينه محرر المحضر بنفساه.

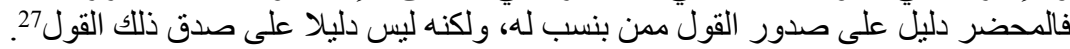

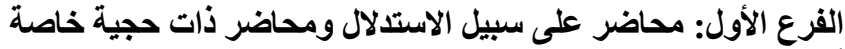
أولا- المحاضر التي تعتبر مجرد استدلالات الاتل

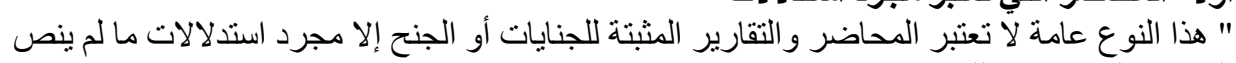

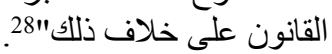

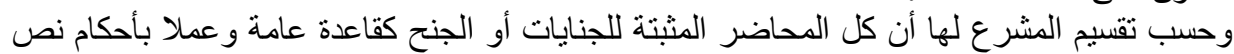

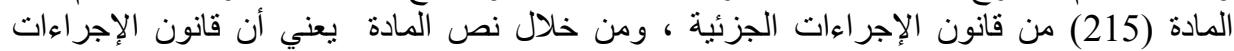

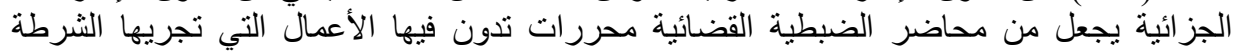

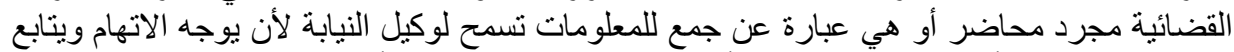

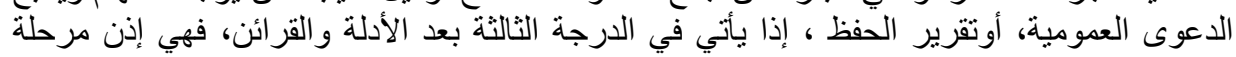

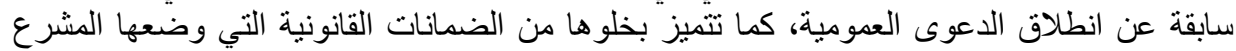

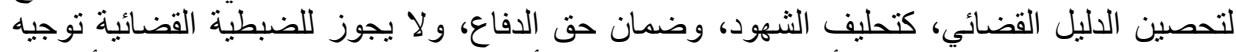

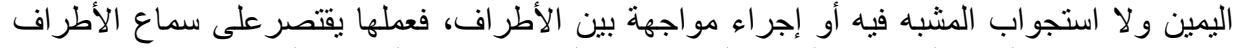

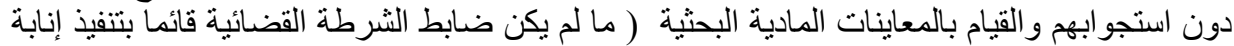
قضائية فعمله حينئذ يعتبر عملا قضائيا) 


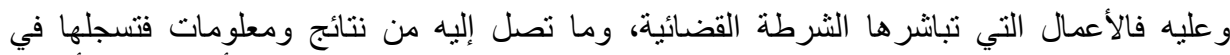

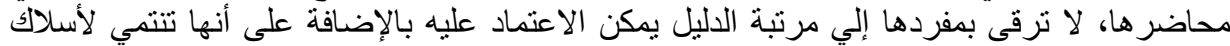

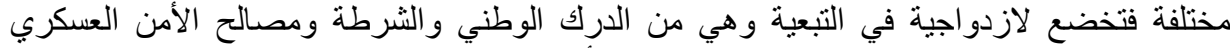

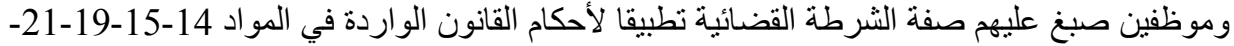

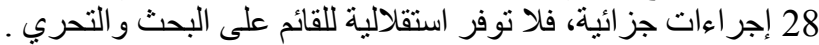

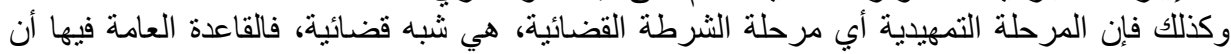

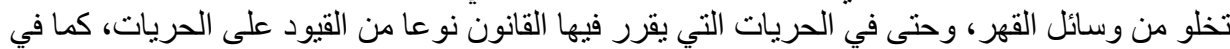

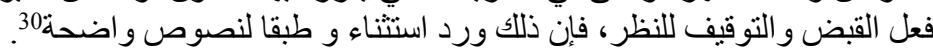

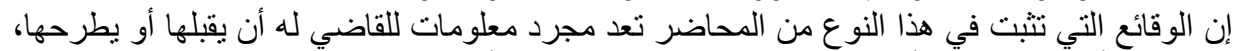

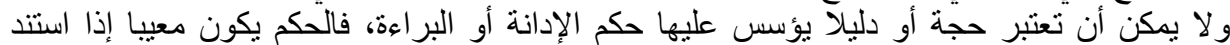

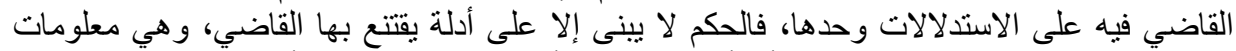

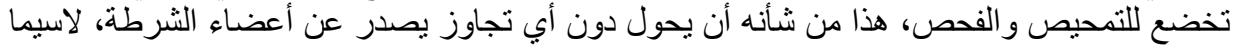

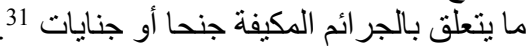

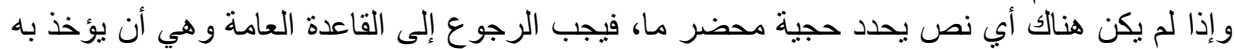

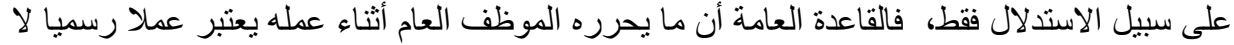

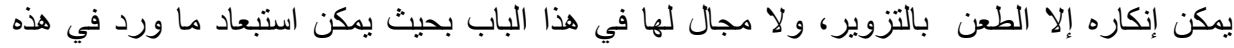

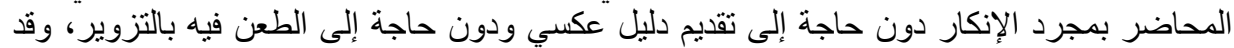

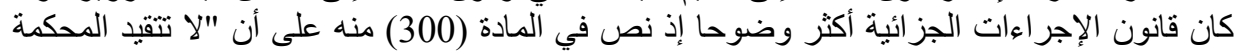

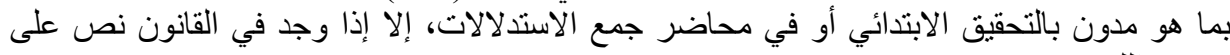

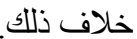

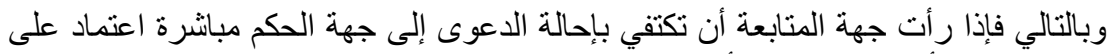

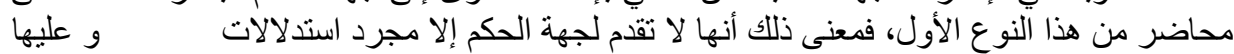

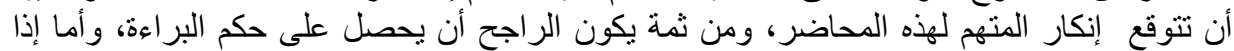

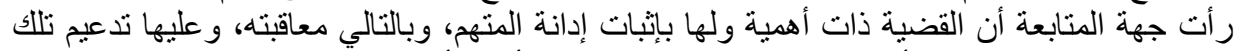

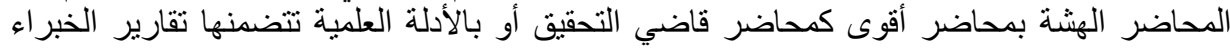

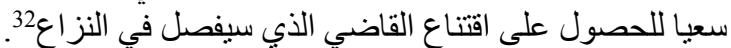

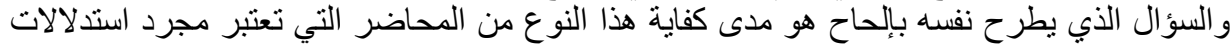

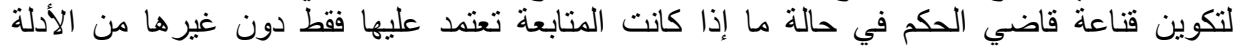
و والقر ائن. فإذا قلنا بأنها غير كافية للإثثبات ولا يجوز الاستتاد عليها بمفردها للنطق بالأدلة كما ذهب إلى ذلك الكا

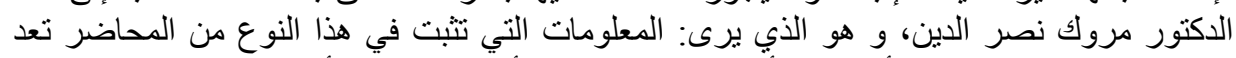

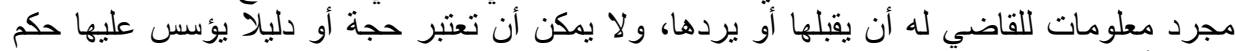

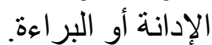

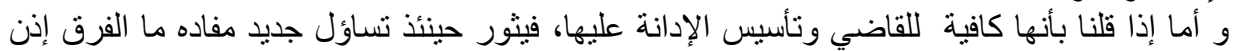

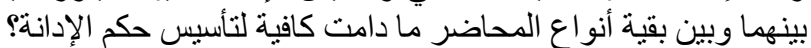

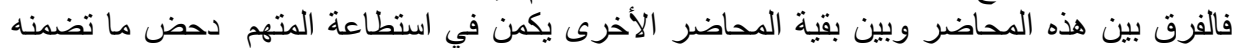

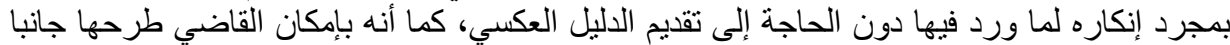

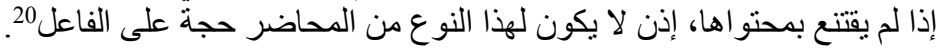


ثانيا- المحاضر التي له حجة حتى تثبت العكس ( محاضر ذات قوة ثبوتية خاصة)

Procés - verbeaux faisant foi jusqu’àpreuve du contraire هذا النوع من المحاضر له حجية، أي أن المحكمة تعتمد عليه لأن ما جاء فيه يُ يعتبر صحيحا إلى أن يثبت

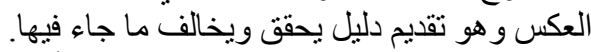

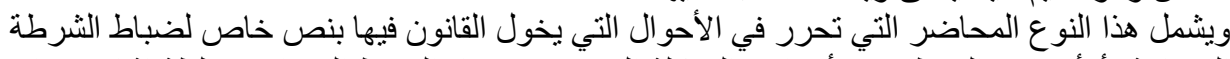

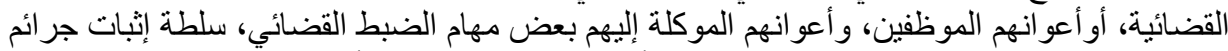

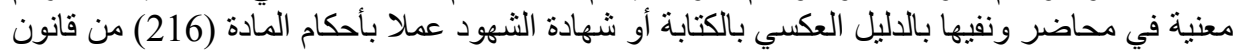

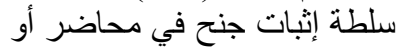

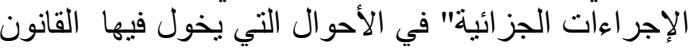

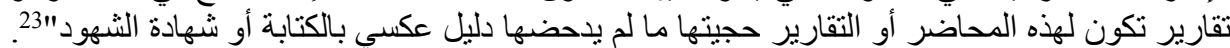

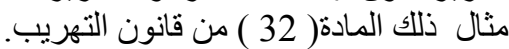

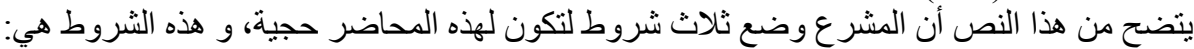

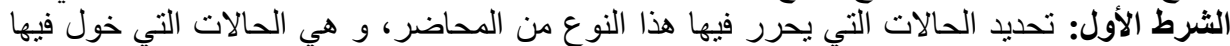

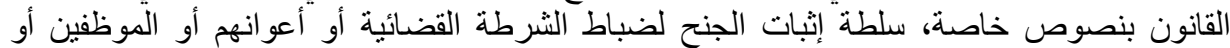

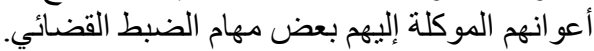

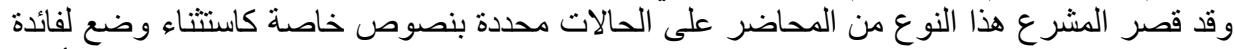

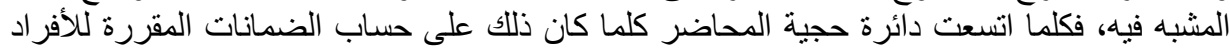

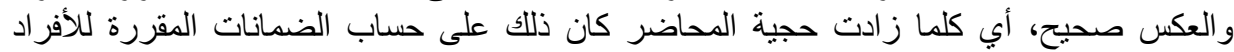

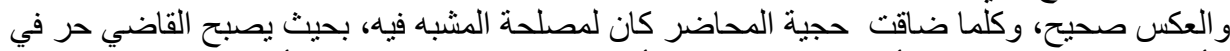

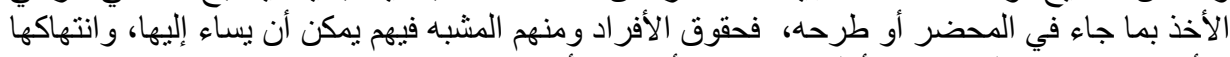

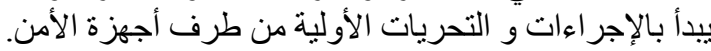

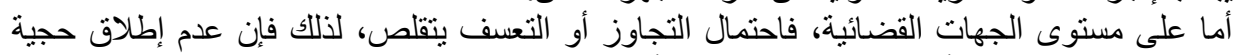

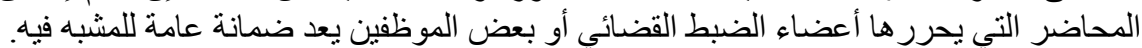

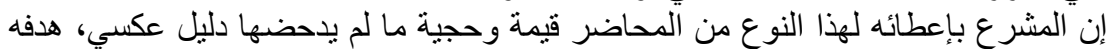

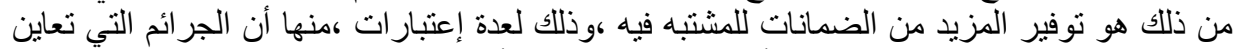

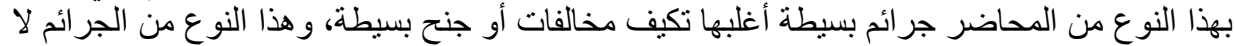

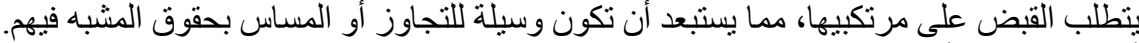

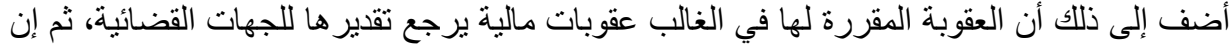

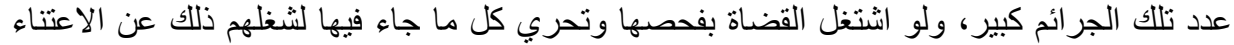

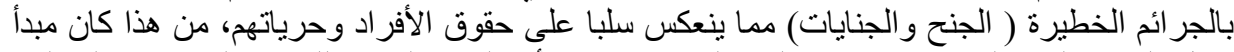

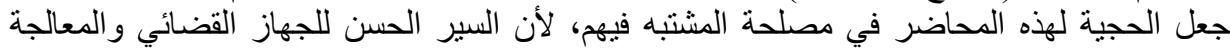

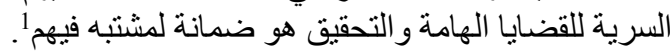

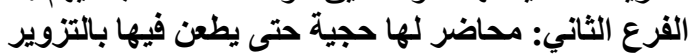

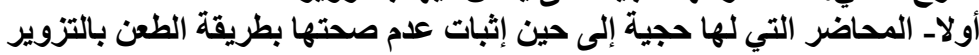

Procés- verbeaux faisant foi jusqu'àinscription de faux. و هذا النوع من المحاضر يحررها أعوان وموظفون مختصون بضبط المخالفات للتشريعات، القائمين

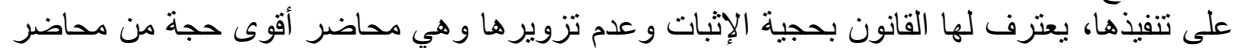

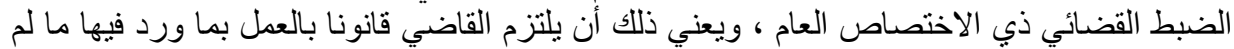

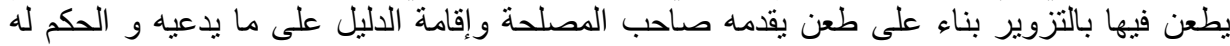

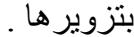

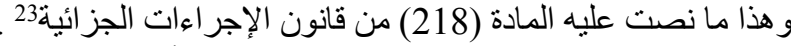
"إن المو اد التي تحرر عنها محاضر لها حجيتها إلى أن يطعن فيها بالتزوير تنظيمها قو انين خاصة". 


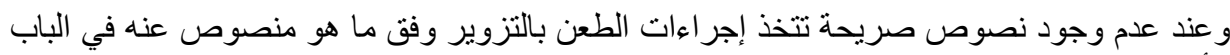
الأول من الكتاب من إلى

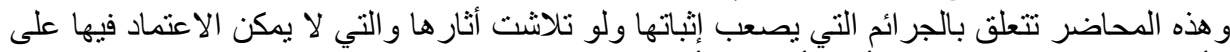

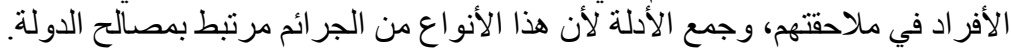

ثانيا- المحاضر ذات القوة الثبوتية المطلقة.

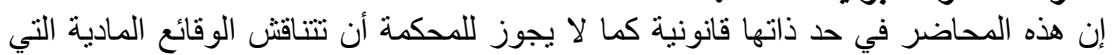

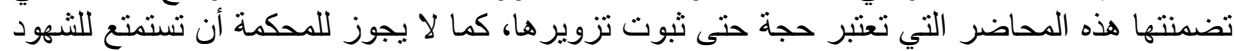

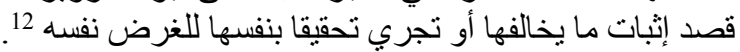

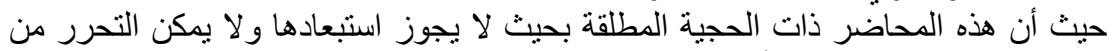

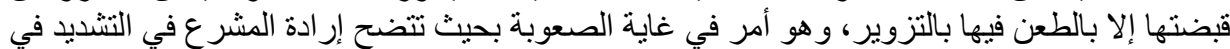

و هذا الدليل ليس من السهل دحضه، و وكأنه لا بريد لجر ائم معنية أن تلفت من العقاب، وابرز

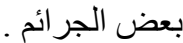

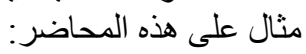

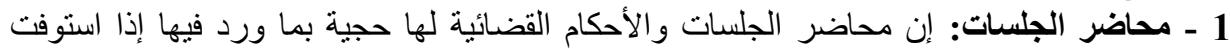

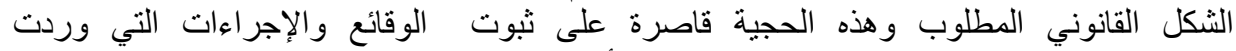

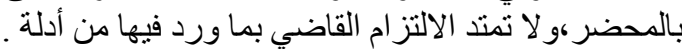

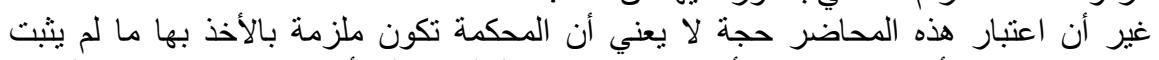

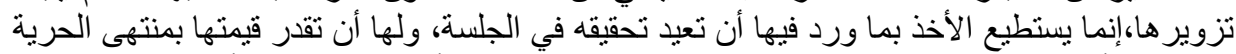

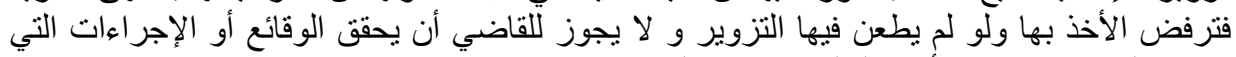

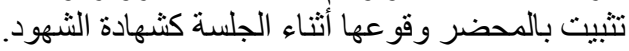

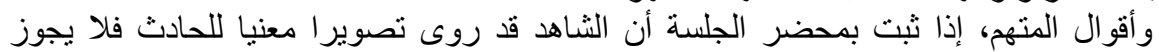

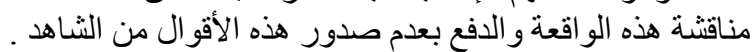

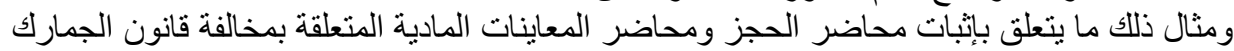

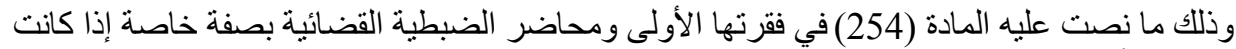

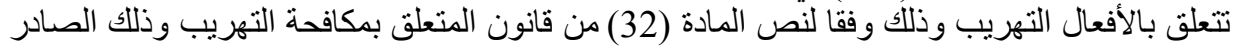

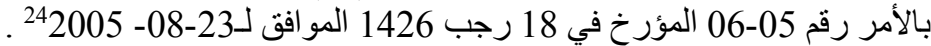

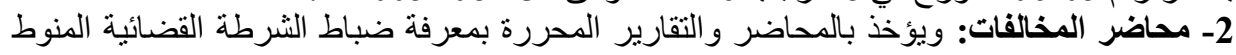

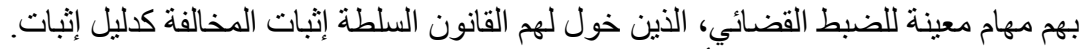

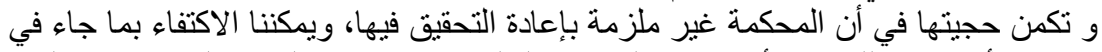

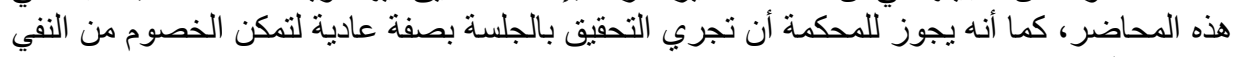
غير أن الحجية الواردة في المحاضر ليست مطلقة وشاملة و إنما تقتصر على العثل الوقائع الدكونة بما جاء بالمحاضر المير

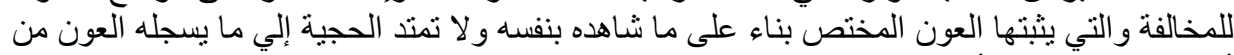

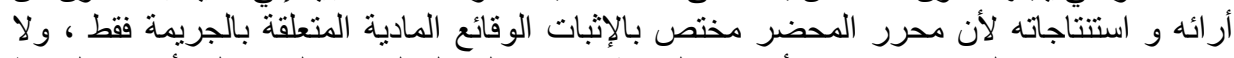

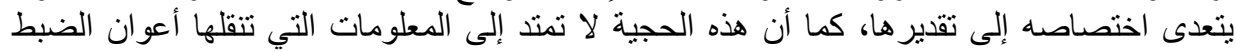

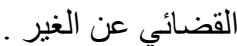

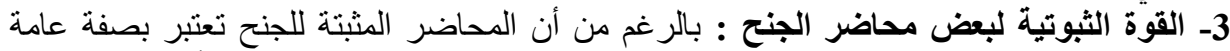

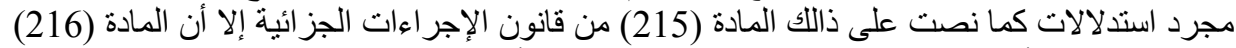

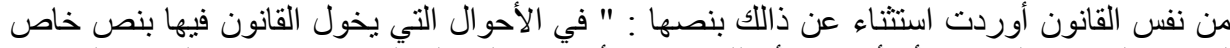

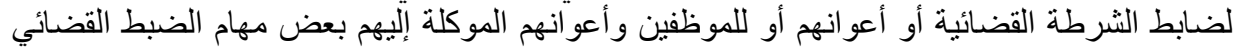

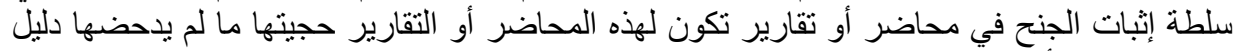
عكسي بالكتابة أو شهادة الثهود " 23. 
- ـو الجدير بالذكر أن الاستثناء الوارد في المادة (216) من قانون الإجراءات الجزائية بتعلق بإنبات

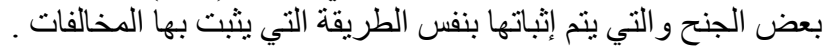

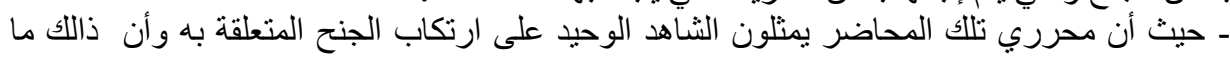

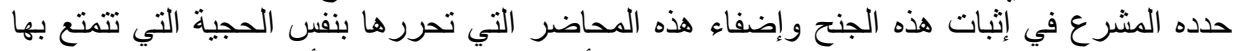

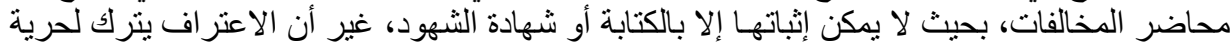

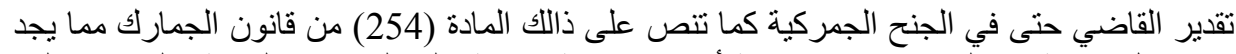

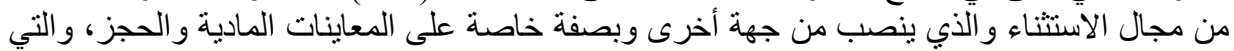

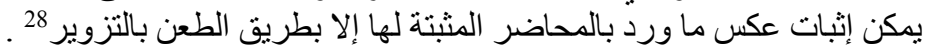

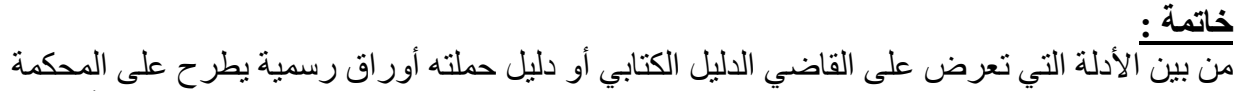

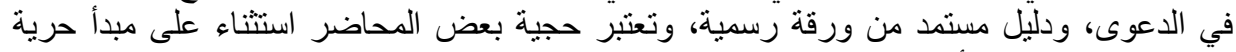

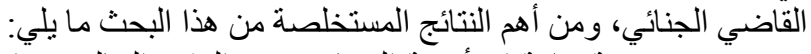

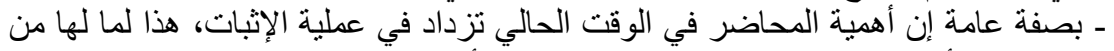

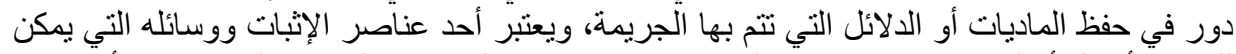

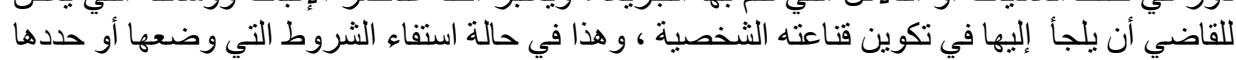

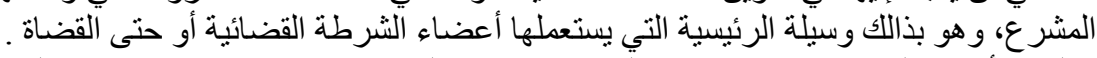

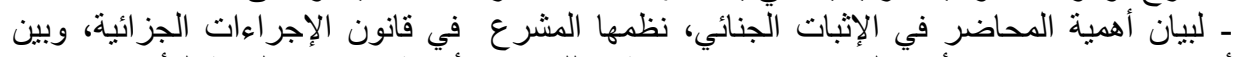

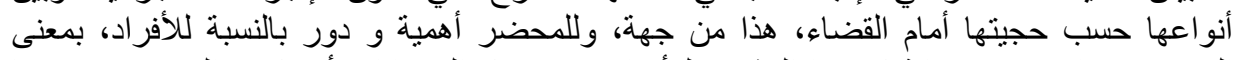

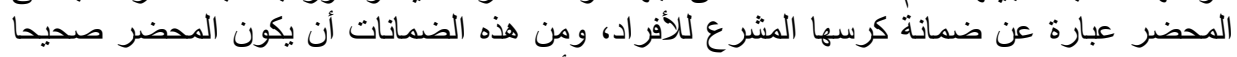

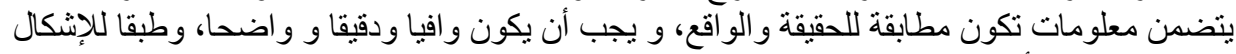

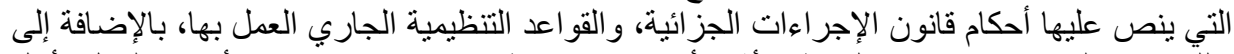

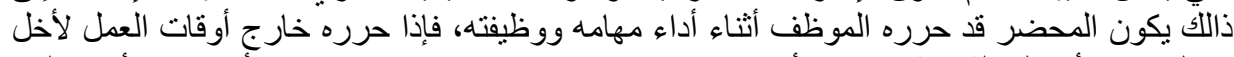

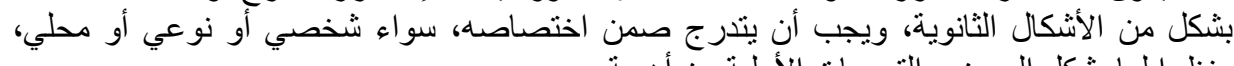

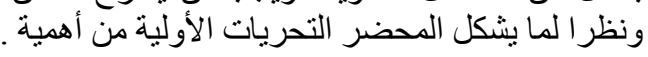

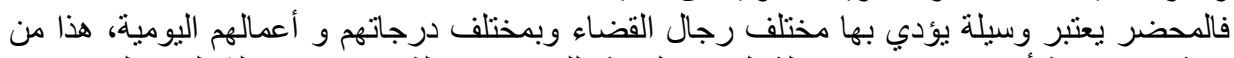

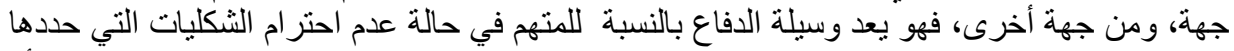

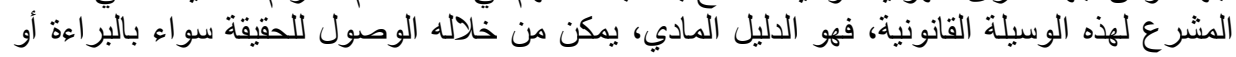

ـ كما أنه لا ترتبط حجية المحضر بالتقدير الذي يذكره صاحب المانب المضر فيما يخص الطابع العمدي

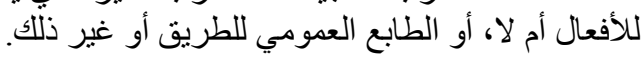

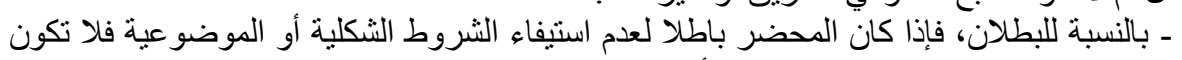

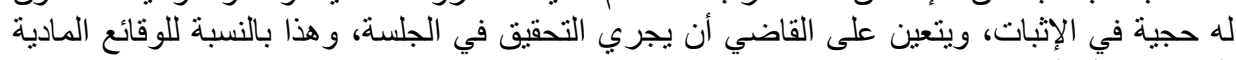

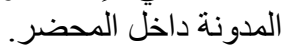

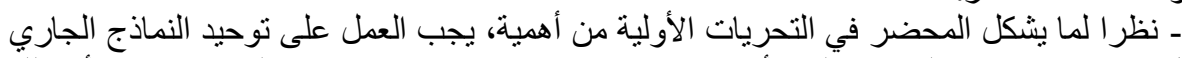

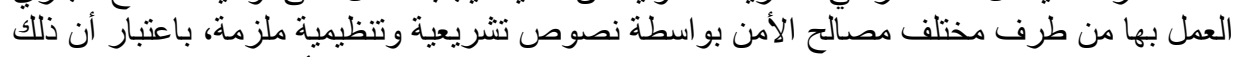

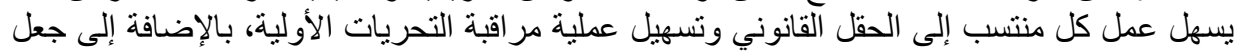
طرق التحري معروفة لدى الجميع.

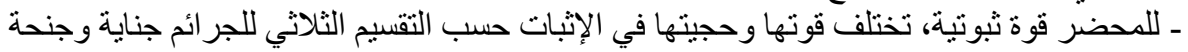

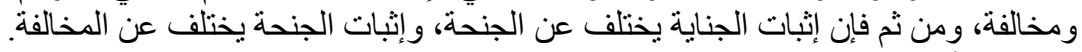

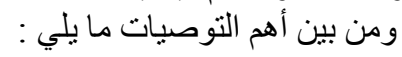
سن قانون خاص بالمحاضر و تتظيمها. 
توحيد نموذج خاص بالمحاضر فيما يتعلق بالعمل به، معروفة لاى الجميع.

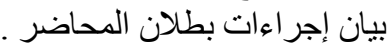

أن ينص على المحضر الالكتروني ، و هذا لتز ايد الجر ائم الالكترونية.

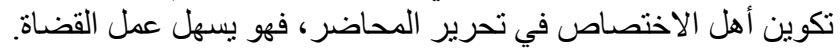

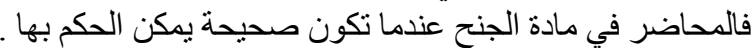

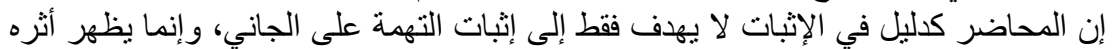

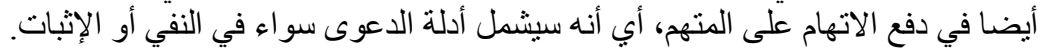

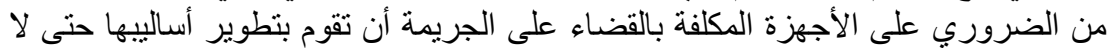
تقتصر على ملاحقة المجرمين، وكثثف جر ائمهم لتصبح دائما في موقف الته التفوق عليهم.

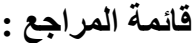

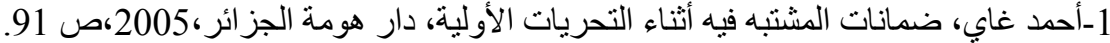

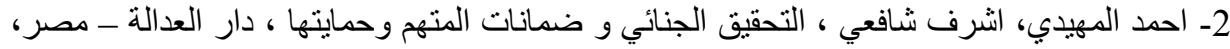

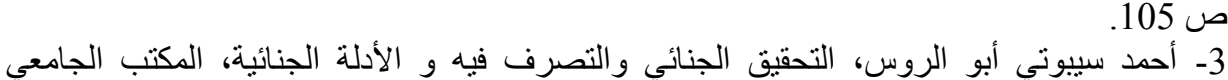

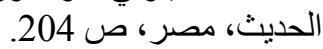

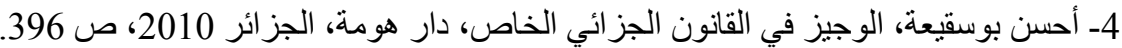

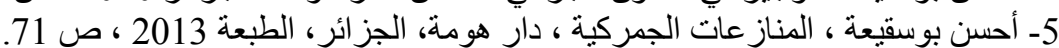

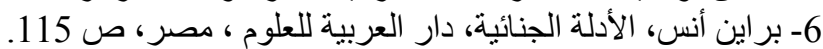
7- هشام الجميلي، الو افي في الإثبات الجنائي، دار الفكر الجامعي، مص، الطئالطبعة 2007 ، ص ص م 215

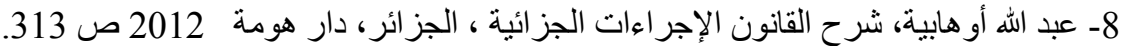

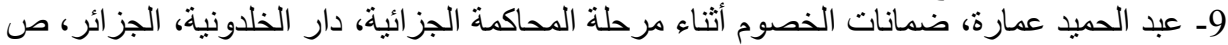

10- عبد الرحمان خلفي، محاضر ات في قانون الإجراءات الجزائية الجزائري، دار الهدى ،عين مليلة،

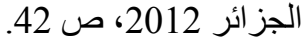

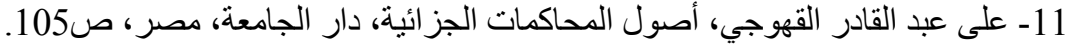

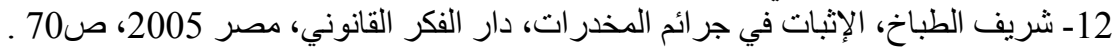

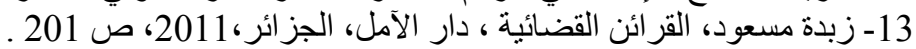

14- فريحة محمد هشام، فريد حسين، شرح قانون الإن الإجر اءات الجز ائية، دار الخلدونية ،

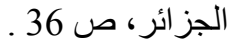

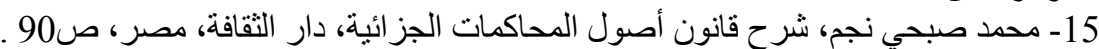

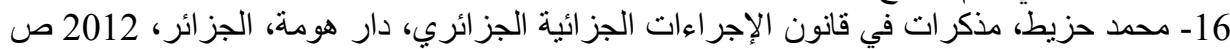

17- مروك نصر الدين، محاضرات في الإثبات الجنائي، الاعتراف، الدحررات ، الجزائر، دار هومة

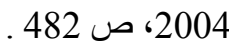

18- محمد مروان، نظام الإثبات في المواد الجنائية في القانون الوضعي الجزائري، المطبوعات

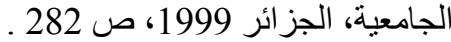

19- محمد أحمد محمود، الوجيز في أدلة الإثبات الجنائي، دار الفكر الجامعي2001، مصر، 
20- منصور عمر المعايطة، الأدلة الجنائية والتحقيق الجنائي، مركز الطب الثرعي، عمان، الأردن،

21- نجيمي جمال ، إثبات الجريمة على ضوء الاجتهاد القضائي،الجز ائر، دار هومة 2011 ،

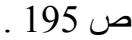

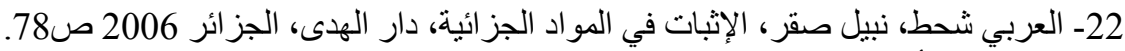

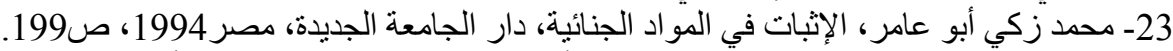

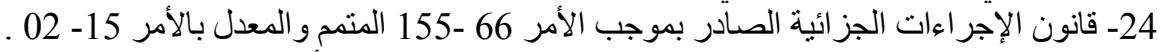

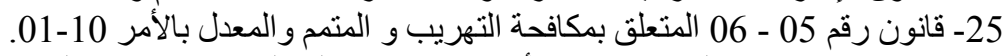

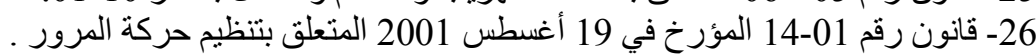

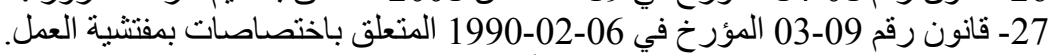

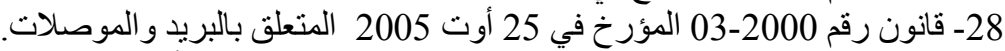

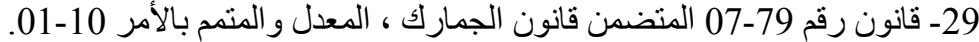

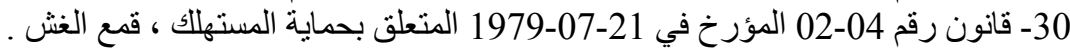

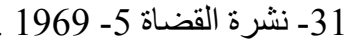

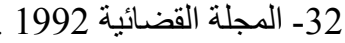

33- جيلالي بغدادي، الاجتهاد القضائي في المو اد الجزائية، الجزء الأول، المؤسسة الوطنية للاتصال

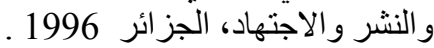

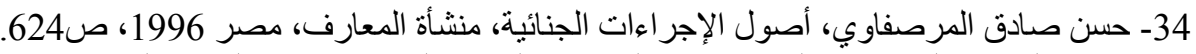

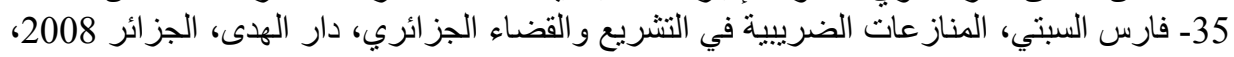

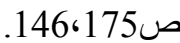
36- جيلالي بغدادي، الاجتهاد القضائي في المواد الجزائية، الجزء الثاني، الطبعة الأولي، الديوان

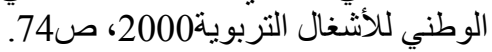

